УДК 528.44

\title{
ТРЕХМЕРНЫЙ КАДАСТР НЕДВИЖИМОСТИ В РОССИИ
}

\author{
К.Ф. Байрактар, магистрант, bairaktar.ksenija@yandex.ru \\ (Тверской государственный технический университет, \\ наб. Аф. Никитина, 22, г. Тверь, 170026, Россия)
}

\begin{abstract}
Аннотация. В данной статье рассмотрены преимущества трехмерного кадастра, предпосылки перехода кадастра в формат 3D, технологии, пригодные для создания трехмерной реальности. Приведены аспекты и разобраны вопросы ведения кадастрового учета, связанного с трехмерным представлением и трехмерной обработкой информации по объектам кадастра. Перечислены основные модели представления 3D-информации.
\end{abstract}

Ключевые слова: 3D-кадастр, трехмерная модель местности, 3D-пространственные объекты, автоматизированные системы трехмерного проектирования, 3D-реальность.

Во всем мире в последние годы обсуждается тема трехмерного (3D) кадастра. Сейчас это особенно актуально, так как современное высокотехнологичное общество все более нуждается в системе получения оперативной, актуальной и достоверной информации о состоянии окружающего нас мира.

В настоящее время в большинстве стран мира, в том числе и в Российской Федерации, кадастр объектов недвижимости ведется в двухмерном виде. Местоположение земельных участков фиксируется внесением в кадастр значений прямоугольных координат точек поворота границ участков. Это обеспечивает точную привязку участков на местности, учет их площади, конфигурации и положения относительно соседних участков. Однако у такого метода есть ряд недостатков. Он не позволяет учитывать многоуровневые объекты: дорожные развязки, мосты и туннели, здания нестандартной формы с нависающими этажами. Кроме того, действующая система учета объектов недвижимости не имеет возможности учитывать особенности рельефа, несомненно, оказывающие существенное влияние на оценку их кадастровой стоимости. В связи с этим возникает необходимость разработки и внедрения на территории РФ трехмерного кадастра недвижимости. Трехмерное отображение поверхности земли и расположенных на ней объектов могло бы значительно расширить возможности кадастрового учета и механизмы обеспечения прав собственности, планирования и проектирования.

На сегодняшний день 3D-кадастр используется и применяется в 24 странах Евросоюза.

В целом он позволяет:

- повысить оперативность и обоснованность принятия решений в области земельно-имущественных отношений;

- повысить устойчивость комплексного управления системой объектов;

- повысить справедливость налогообложения недвижимого имущества;

- создать более благоприятные условия для инвестирования в сферу земельно-кадастровых отношений;

- повысить гарантии прав владельцев недвижимости;

- повысить актуальность сведений.

Возможности 3D кадастра:

- многоцелевое использование поверхностных участков земли;

- многоцелевое использование надземных участков;

- многоцелевое использование подземных участков.

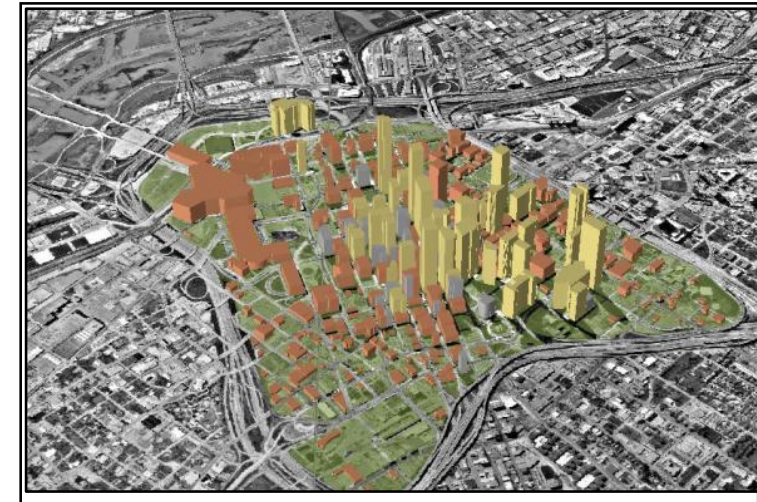

Рис. 1. Трехмерная модель местности
Исходя из опыта создания трехмерного кадастра ряда европейских стран и учитывая, что в настоящее время при проектировании зданий или сооружений (будущих объектов кадастрового учета) широко используются автоматизированные системы трехмерного проектирования, можно предположить, что базой для трехмерного кадастра будут трехмерные геоинформационные системы (ГИС). Первым этапом их формирования является создание трехмерных моделей местности (рис. 1).

Современный уровень развития технологий позволяет выполнять эту работу максимально оперативно. Технологическими решениями, признанными эффективными для получения пространственной информа- 
ции при моделировании реальных объектов, являются аэрофотосъемка и трехмерное лазерное сканирование.

Данные для аэросъемочных работ - плановые аэрофотоснимки, на основе которых в дальнейшем создают ортофотопланы (рис. 2). Трехмерные модели получают путем стереоскопической обработки ортофотопланов, по которым легко измерять реальную высоту любого объекта. Для представления стен зданий и вертикальных поверхностей традиционно используются данные наземной фотосъемки. Такой способ сбора информации весьма трудоемкий, так как сфотографировать все фасады зданий крайне затруднительно.

Производители аэросъемочной аппаратуры предлагают принципиально новое решение - совмещение плановой и перспективной (наклонной) аэросъемки. Это дает существенную экономию времени и ресурсов заказчика работ.
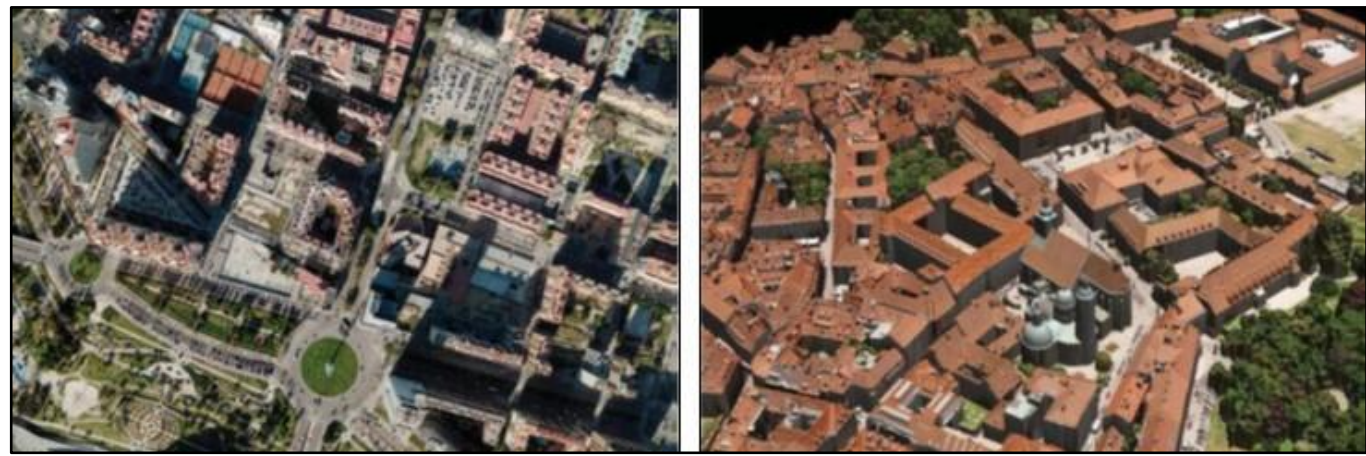

Рис. 2. Цифровая модель местности, построенная по плановому аэрофотоснимку

Трехмерное лазерное сканирование - съемочная система, измеряющая с высокой скоростью (от нескольких тысяч до миллиона точек в секунду) расстояния от сканера до поверхности объекта и регистрирующая соответствующие направления (вертикальные и горизонтальные углы) с последующим формированием трехмерного изображения (скана) в виде «облака точек» (рис. 3), является сравнительно молодым направлением в области высокоточных измерений.

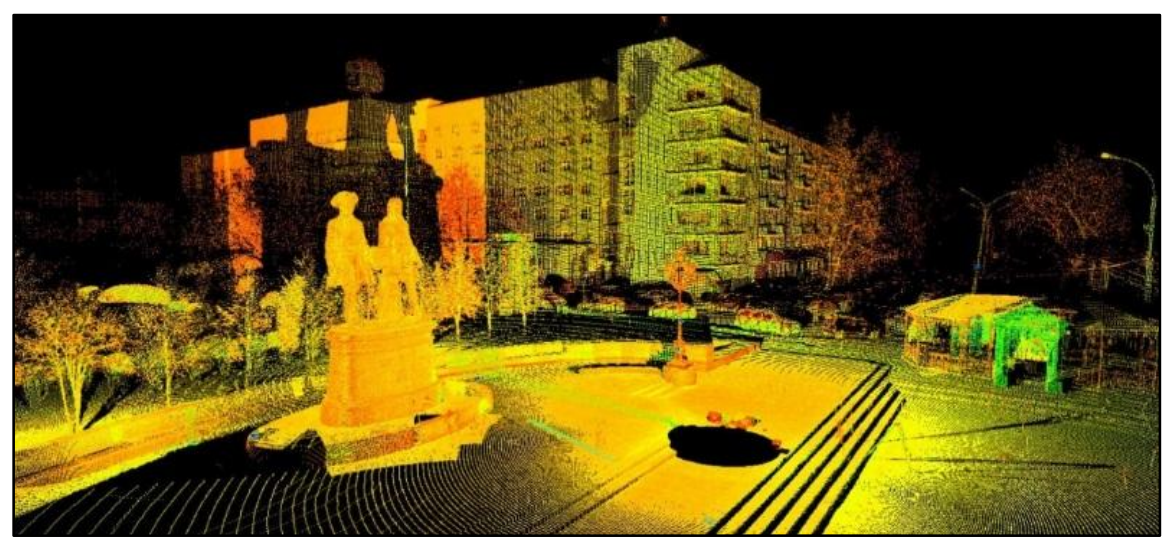

Рис. 3. «Облако точек» лазерных отражений

Обе технологии пригодны для создания трехмерной реальности. Первая идеально подходит для высокоточного моделирования больших по площади территорий, вторая эффективна при высокой плотности застройки и необходимости получения точной трехмерной модели с предельной погрешностью расчетов до 2 см. На основе полученных трехмерных моделей и современных ГИС возможно создание геоинформационных проектов, которые не только позволят отобразить различную информацию об объектах (их название, назначение, кадастровый или условный номер, адрес, фактические внешние размеры, этажность, материал постройки, форму собственности, вид права и его ограничения), но и обеспечат полноценную визуализацию и пространственный анализ. Кроме того, их можно будет использовать для решения широкого спектра задач, связанных с анализом явлений и событий, прогнозированием их вероятных последствий, планированием стратегических решений.

С мая 2010 г. по июнь 2012 г. в России в рамках программы «Правительство для правительства» (G2G) Федеральной службой государственной регистрации, кадастра и картографии России и Агентст- 
вом кадастра, регистрации земель и картографии Нидерландов был выполнен пилотный проект «Создание модели трехмерного кадастра недвижимости в России».

В рамках проекта сделан выбор в пользу юридического 3D-кадастра на основе объемных объектов или 3D-парцелл. 3D-парцелла - это «юридический объект», отображающий часть пространства, то есть пространственная единица, у которой одно или несколько уникальных прав (например, право собственности или право пользования), обременения и ограничения связаны со всем объектом, включенным в систему управления недвижимостью. Этих объемных объектов как таковых в российском кадастровом учете нет. Однако существующий кадастровый учет кадастровых объектов, отличных от 2D-кадастра земельных участков, дает достаточную основу для расширения этого учета до 3D-кадастра. Первый вариант для 3D-кадастра в России - прямо разрешить 3D-представления в пяти известных видах кадастровых объектов. Эти кадастровые объекты могли бы рассматриваться как 3D-парцеллы в системе предлагаемого 3D-кадастра. Границы этих 3D-парцелл определяются физическими границами сооружения или части сооружения (здания, помещения, трубопровода и т.д.). Также все эти объекты имеют кадастровый идентификатор и поэтому могли бы рассматриваться как 3D-парцеллы. Это сделает возможным регистрацию прав и ограничений на эти 3D-парцеллы.

Применение 3D-кадастра согласуется с современным уровнем развития информационных технологий Росреестра. По этой причине после первоначальной разработки системы (расширения) дополнительные затраты практически не нужны, а ее введение не повлияет на процессы регистрации прав и кадастрового учета. При этом следует учитывать, что новые объекты кадастрового учета (новые здания или сооружения) часто архитектурно проектируются (CAD) непосредственно в 3D. Таким образом, лишь с небольшими дополнительными усилиями (при наличии четких инструкций) можно использовать 3D-объекты для кадастрового учета и регистрации прав.

В ходе дальнейшего развития 3D-кадастра Росреестру необходимо разработать производственную среду с большей функциональностью, в том числе систему проверки, систему управления базами данных (СУБД) для хранения данных, создание «на лету» потока XML/X3D-данных из БД, а также расширение 3D-визуализации для отображения соседних единиц в 3D. Система проверки должна автоматически проверять 3D-кадастровые объекты по отношению к формальным правилам, прежде чем новые объекты будут приняты и сохранены в СУБД.

Главная проблема для Росреестра - внедрение автоматизации решения новых задач с особым упором на проверку данных о трехмерных объектах. Если Росреестр успешно решит эти задачи, дополнительные затраты на изменения в организации будут минимальными. Но можно ожидать, что даже за пределами Росреестра затраты не будут огромными. С использованием 3D-программного обеспечения уже проектируется много новых зданий, и 3D-кадастровая информация может быть легко получена из этих проектов. Для существующих объектов, которые должны быть зарегистрированы как 3D-объекты, существуют два варианта: создание моделей на основе поэтажных планов либо их измерение заново, например, с применением лазерного сканирования.

Развитие работ по введению 3D-кадастра и взаимодействие с потенциальными пользователями как в системе Росреестра, так и с более широким кругом потребителей позволят выявить наиболее эффективные пути реализации и уточнить состав информационных продуктов, создаваемых с использованием данных трехмерного кадастра по сложным объектам недвижимости. Самое большое изменение будет в работе кадастровых инженеров, которым придется адаптировать свои методы измерения 3D-объектов, но это произойдет вне сферы Росреестра. В переходный период Росреестру может потребоваться поддержка поставщиков программного обеспечения для адаптации к их продукции и инженеров в их новом методе работы.

Российский кадастр связан с рядом проблем, которые нужно решить, чтобы принять аспекты 3Dреальности. Одним из основных вопросов трехмерного кадастра является его правовая составляющая. Законодательство Российской Федерации в сфере государственной регистрации прав на недвижимое имущество и сделок с ним и государственного кадастрового учета не содержит упоминаний о 3Dобъектах, в то же время отсутствуют препятствия для их кадастрового учета и государственной регистрации.

При переходе к полноценному трехмерному кадастру на территории Российской Федерации не менее важным является экономический аспект. Но, учитывая, что применение 3D-кадастра согласуется с современным уровнем развития информационных технологий Росреестра, этот переход оправдан.

Нужно идти в ногу со временем, совершенствовать государственную регистрацию и кадастр недвижимости, расширять предоставление услуг в электронном виде различным категориям потребителей, поэтому кадастр в формате 3D России необходим. Он будет способствовать защите интересов государства, бизнеса и граждан и станет незаменимым инструментом визуализации, который позволит принимать решения значительно быстрее и эффективнее. Ведение 3D-кадастра позволит со временем осуществить переход на 4D-кадастр, когда можно будет увидеть изменение объекта и имущественных прав на него во времени. 


\section{Литература}

1. Лисицкий Д.В., Нгуен Ань Тай. Пространственная локализация и правила цифрового описания объектов в трехмерном картографировании // Изв. вузов. Геодезия и аэрофотосъемка. 2013. № 4. С. 190 195.

2. Официальный сайт Росреестра по Нижегородской области. URL: http://www.to52.rosreestr.ru/ news/media/1420745/ (дата обращения: 04.05.2015).

3. Герасимова С.Г., Ибрагимов М.Б., Петров М.В. Перспективы создания 3D кадастра в России. URL: http://www.geoprofi.ru/technology/Article_6416_10.htm (дата обращения: 04.05.2015).

4. Малыгина О.И. Трехмерный кадастр - основа развития современного мегаполиса. URL: http://www.elibrary.ru (дата обращения: 04.05.2015). 